\title{
A Review on Application of Gases for Aluminium Refining
}

\section{Saravanakumar $P^{\# 1}$, Manojkumar $M^{\# 2}$, Naveenkumar $S^{\# 3}$, Ranjithsudharshan $G^{\# 4}$}

\#1 Assistant Professor, Department of Mechanical Engineering, Sri Ramakrishna Engineering

College, Coimbatore, Tamilnadu, India,Ph: 8825895198

\#2 UG Student, Department of Mechanical Engineering, Sri Ramakrishna Engineering College,

Coimbatore, Tamilnadu, India,Ph: 8015494181

\#3UG Student, Department of Mechanical Engineering, Sri Ramakrishna Engineering College,

Coimbatore, Tamilnadu, India,Ph: 9629448401

\#4 UG Student, Department of Mechanical Engineering, Sri Ramakrishna Engineering

College, Coimbatore, Tamilnadu, India,Ph: 9042472494

\section{ABSTRACT}

Aluminium recycling has gained focus in the recent years due to the profound application of aluminium. In addition to that the world is moving towards the method of sustainable method of production. Aluminium recycling consumes only 5\% of the energy required for the production of aluminium through traditional method. Recycling is beneficial in terms of reduction in energy, usage of conventional natural resources, waste disposal in landfills, emission of greenhouse gases that lessen global warming and production costs Currently, the refining of aluminium is restricted to removal of alkali or alkali earth metals, non-metallic inclusions and hydrogen. Technologies for removal of these types are commercially mature and there is a need for focus on the removal of other undesirable or tramp elements such as copper, silicon, iron, iron or zinc from the aluminium melt and application of chlorine must be discouraged due to their toxic nature. Considering these problems, a review has been conducted to evaluate the current practice in the refining of aluminium alloys by the application of gas to eliminate the defects in aluminium castings. The study has been extended to focus on the various techniques that are applied for the cleaning of melt.

Keywords: Aluminium, recycling, gas, degassing, floatation, filtration, sedimentation

\section{INTRODUCTION}

The third most generous supply from our earth's crust is aluminium. It does not occur in the free elemental state. It is available as a combined chemical compound. In the early years, the metal was highly expensive and therefore had limited application. It was in the year 1890, the Hall-Heroult process was staged as the most economic and viable means for extraction of aluminium. Since then, the material had diverse applications numerous fields of science and engineering due to their unique properties. The metal is known for its high strength to weight ratio. This encourages consumers to apply aluminium in several sectors like medical, aerospace, automobile, and electrical and electronics are profoundly replacing aluminium over steel. In addition to that, this super metal encompasses several other immense properties like low density, thermal and electrical conductivity, corrosion resistance, magnetic neutrality, ductility and malleability[1][2][3].

Currently, many national governments and industries are stressing on increasing the energy efficiency and reducing the level of greenhouse gas emission. Therefore, a sustainable procedure of aluminium production has gained the focus in the past few decades[4]. Traditional market drivers (price, technical performance etc.,) are complemented by environmental and other sustainable products. Therefore, there is a need for resource efficient products[5]. Aluminium recycling process is benefitted by saving the energy by approximately $95 \%$, environment by decreasing the greenhouse gas emissions, reducing space for landfills and costs by lessening the capital expenditures[6]. Currently, around 50-60\% of aluminium alloys are recycled at the end of its life[7]. In developing countries like India, the recycling industry can develop vigorously to make profits. For efficient recycling, several 
issues such as scrap sampling, scrap purchasing, metal recovery, yield, production cost and product quality, environmental issues and regulation must be addressed[8].

One of the main defects in aluminium alloys is porosity. It is undesirable to the mechanical properties, surface quality, and corrosion resistance. Therefore, porosity must be eliminates prior to solidification[9]. Defects such as porosities in a casting are caused due to the gases present in the liquid melt. However, the solubility of gases in the solid is much lesser than the solubility in the liquid state. Hydrogen is major gas that leads to porosity defects in aluminium castings. There are numerous sources for hydrogen like atmosphere, scrap, ingots, flux, furnace skin etc. Therefore, degassing operations are vital in casting aluminium for wrought applications[10]. Significant number of degassing techniques is currently applied to remove hydrogen from the aluminium melt. Some degassing techniques include spray degassing, vacuum degassing, gas degassing, tablet degassing, rotary degassing, ultrasonic degassing etc.[11]. Table 1 portrays the evolution of this elicit technology over the years.

Table 1: Evolution of degassing technology[12]

\begin{tabular}{|c|c|c|c|c|c|}
\hline Year & 1920ies & 1930ies & 1960ies & 1970ies & 1990ies \\
\hline Technology & $\begin{array}{c}\text { Gas purging } \\
\text { with pure } \\
\text { Chlorine }\end{array}$ & $\begin{array}{c}\text { Chlorine and } \\
\text { nitrogen } \\
\text { mixture } \\
\text { injection }\end{array}$ & $\begin{array}{c}\text { Tri-gas } \\
\text { mixture: Co- } \\
\text { Cl-inert gas } \\
\text { injection. }\end{array}$ & $\begin{array}{c}\text { Jet injection } \\
\text { using nozzle, } \\
\text { porous plug, } \\
\text { Rotary gas } \\
\text { injection }\end{array}$ & $\begin{array}{c}\text { Rotary Flux } \\
\text { Injection of } \\
\text { gas. }\end{array}$ \\
\hline
\end{tabular}

The usage of gases for the refining of aluminium is profoundly applied in many aluminium production industries as they are economical, environment friendly and efficient in removal of gases. The present paper will review the novel method gas degassing technique with the perspective of economic, environmental and energy domains and stretches to investigate the latest technologies developed for aluminium refining and their utility for future research.

\section{REMOVAL OF MAGNESIUM}

Magnesium is an important element present in almost all the aluminium alloys. The magnesium content of the scrap is often in the range of $0.3-0.5 \%$ and the magnesium level required in the most of the alloys are usually $0.1-0.3 \%$. Therefore during the recycling process, the $\mathrm{Mg}$ content has to be controlled. Over the years, removal of magnesium is done thermodynamically by the process of chlorination and it is proved to be the most potential and economical reductant of magnesium. [13][16]. Application of chlorine not only reduces the magnesium content in the melt but also assists the removal of alkali metals, alkali earth metals, hydrogen. In addition to that, phase separation between the liquid metal and solid inclusions is also achieved[13], [17].

Upon chlorine impingement, the following sequence of reactions occurs in the melt[14]-[16]. Direct reaction:

Indirect reaction:

$$
\mathrm{Mg}(\text { in } \mathrm{Al})+\mathrm{Cl}_{2}(\mathrm{~g})=\mathrm{MgCl}_{2}
$$

$$
\begin{aligned}
& 2 / 3 \mathrm{Al}(\mathrm{l})+\mathrm{Cl}_{2}(\mathrm{~g})=2 / 3 \mathrm{AlCl}_{3}(\mathrm{~g}) \\
& \left.2 / 3 \mathrm{AlCl}_{3}(\mathrm{~g})+\mathrm{Mg} \text { (in } \mathrm{Al}\right)=2 / 3 \mathrm{Al}+\mathrm{MgCl}_{2}
\end{aligned}
$$

As shown in the fig. 6 below, there are numerous factors that affect efficient degassing. Fig.6a is an experimental result obtained by Vieira et al[17]. Argon gas was purged into the aluminium melt at various velocities and it was found that the oxide layer on the surface prevents the melt from further oxidation. However, the gas bubbles produced by the degasser disturb the surface oxide layer formed on the melt surface. This discontinuity of the oxide layer increases the oxidation of magnesium and removal of hydrogen present in the melt. 
From Fig.6b, it is evident that removal of magnesium increases with increase in temperature. Velasco et al[14] and Majidi et al[18] recommended a minimum temperature of the melt to be $710^{\circ} \mathrm{C}$ for efficient degassing operation because the melting point of $\mathrm{MgCl}_{2}$ is above $710^{\circ} \mathrm{C}$. Below this temperature Chloride emissions were observed which are harmful to the environment

From Fig.6c, it is evident that the magnesium removal rate increases with the increase in volume flow rate of the gas[15].

In Fig.6d, increased $\mathrm{cl}_{2}$ ratio in the mixture increases removal of magnesium. For efficient demagging, chlorine injection should be three times the magnesium content of the melt i.e. a stoichiometric ratio of 3:1 should be maintained for efficient reaction[14]. Therefore, if $50 \mathrm{lbs}$ of magnesium need to be removed in an hour, $150 \mathrm{lbs}$ of chlorine must be injected. The condition maintained must be optimized for magnesium chloride generation and reduction of aluminium chloride and chlorine emissions. Therefore for good demagging, good mixing and maximization of reaction interface area and bubble residence time is essential. Demagging can be performed with fused salts alone. But the disadvantage is the bulk salt produced and reaction efficiency. The efficiency of the reaction depends on the availability of magnesium. As the magnesium in the melt decreases, the formation of aluminium chloride increases[16].
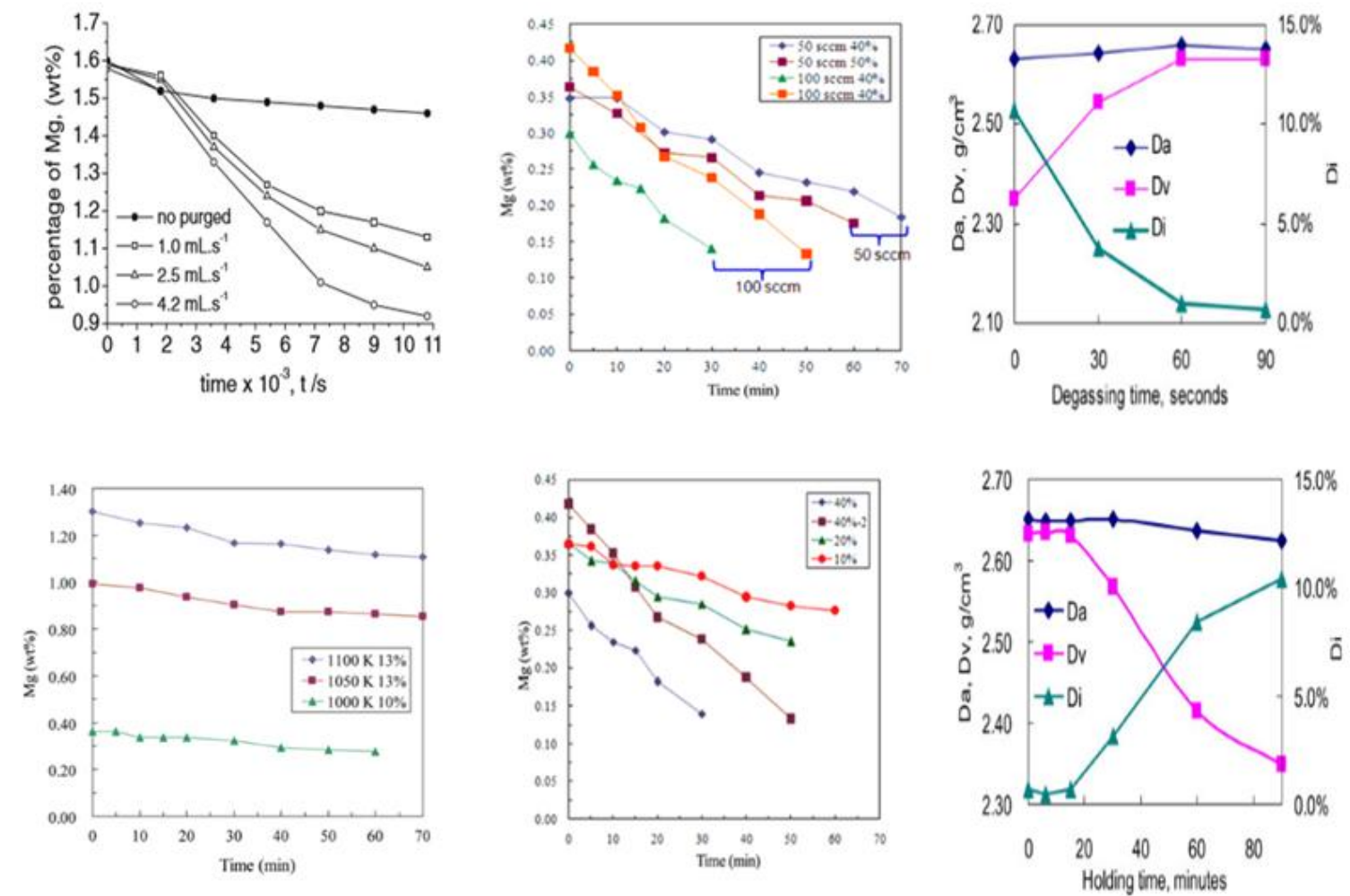

Figure1: Mg concentration with: a) Velocity of purging gas[17], b) Temperature of degassing[18], c) Gas flow rate[15], d) Ratio of $\mathrm{Cl}_{2}$ [14], e) Degassing time[9], f) Holding time after degassing[9]

Zuo et al[9] in his experiment used rotary degassing technology. In Fig.6e, Di refers to the density Index; Da is the density of sample solidified in the air and Dv is the density of sample solidified in a vacuum. Di value decreases rapidly within the first 30s; slow decrease in the next 30s and after 60s, Di remains almost constant. Zuo et al recommend an optimum time for degassing with rotary degasser to be $60-90 \mathrm{~s}$. He proposed that for rotary degassing, a degassing time of 60 seconds is significant.

Holding time after degassing plays a crucial role in the efficiency of degassing process because there is the possibility of re-gassing. If the environment present outside the surface of the melt is water vapour, there is a high possibility of hydrogen diffusion. From Fig.6f, it is evident that degassing efficiency decreases with the increasing holding time. Therefore Zuo et al recommend a holding time within 15 minutes after degassing. 


\section{MECHANISM OF DEGASSING}

In addition to the above factors, the size of the gas bubbles produced inside the melt also contributes an important factor for degassing. Intensive melt shearing produces smaller bubbles which are effectively dispersed and distributed throughout the melt. Small sized bubbles have less floatation, therefore, the residual time of the smaller bubbles in the melt are higher. Also due to their good dispersion, there is a shorter diffusion distance from hydrogen present in the melt. The hydrogen present in the liquid melt diffuses into the argon bubble due to the difference in the partial pressure and thereby reducing the hydrogen concentration in the melt[9], [19]. However, the size of the bubble depends on the pore diameter and the gas flow rate.

The effectiveness of gas purging operations depends on the kinetics of the reactions during the degassing process. The speed of the hydrogen removal can be described by a first order reaction and roughly by the equation:

$$
d_{C H} / d t=(-\beta \times A) / V
$$

Maniruzzaman et al[20] developed a mathematical model for the simulation of the flow inside the melt in a treatment furnace. Various process parameters that affect the performance of the degassing by a rotary impeller were studied. Table 2 portrayed below shows the effects of different parameters on melt degassing.

Table 2: Effect of different parameter in degassing[20]

\begin{tabular}{|c|l|l|}
\hline S.NO & \multicolumn{1}{|c|}{ Factor } & \multicolumn{1}{|c|}{ Percent Contribution } \\
\hline 1. & Rotation Speed & 74.37 \\
\hline 2. & Gas Flow Rate & 3.05 \\
\hline 3. & Speed X Gas Flow Rate & 3.04 \\
\hline 4. & Rotation direction & 6.16 \\
\hline 5. & Speed X Rotation direction & 6.12 \\
\hline 6. & Gas flow rate XRotation direction & - \\
\hline 7. & Duration & - \\
\hline
\end{tabular}

\section{LATEST TECHNOLOGIES}

The decrease of the hydrogen concentration in the melt $\mathrm{c}$ depends on

- Retention time $\mathrm{t}$ of the bubble

- Mass-transfer coefficient $\beta$,

- Melt volume V, and

- Mass-transfer area A

As the retention time of the gas bubble is vital, the depth of the aluminium melt is also an important phenomenon. The latest technology in gas purging is the implementation of RFI (Rotary Flux Injection) technology. The main concern of this development is to use salt flux during injection with inert to decrease the usage of chlorine in the process as a means for protecting the environment from chlorine emissions[12]. Table 2 shown below depicts the different methodologies currently available for melt cleaning.

Table 3: Different Principles of Melt Cleaning[12]

\begin{tabular}{|c|c|c|}
\hline Melt Treatment & Reactants & Removal of \\
\hline Gas Purging & $\mathrm{Cl}_{2}, \mathrm{Ar}_{2} \mathrm{~N}_{2}$ & $\mathrm{H}_{2}$, Alkalines and Inclusions \\
\hline Chlorination & $\mathrm{Cl}_{2}$ & Magnesium, Alkalines \\
\hline Vacuum Treatment & - & $\mathrm{Mg}, \mathrm{Zn}, \mathrm{Pb}, \mathrm{H}_{2}$ \\
\hline Filtration & Ceramic Foam & Inclusions \\
\hline Settling & Time & Inclusions (Al2O3, MgO etc.) \\
\hline Slag Treatment & $\mathrm{NaCl}$, KClInclusions & Inclusions (Al2O3, MgO etc.) \\
\hline
\end{tabular}


Zhao et al[11] studied the mechanism of the evolution of gas bubbles by the application of X-ray micro-focus radiography. The experimental results have shown that re-melting provides profound degassing effect for aluminium alloys. In the Remelting process, the inclusions and oxides are depleted efficiently as most of them are attached to the porosity during solidification. The pores heterogeneously nucleate from the inclusion and grow. The surface of the melt is calm during re-melting and hence less oxide inclusions are entrapped into the melt compared to the traditional melt shearing. Therefore, it reduces the defects in the aluminium casting.

Henderson et al[13] focused on the nozzle configuration that discharges the gases into the melt as it determines the productivity and environment acceptability. The developed gas pump is shown in figure 2.

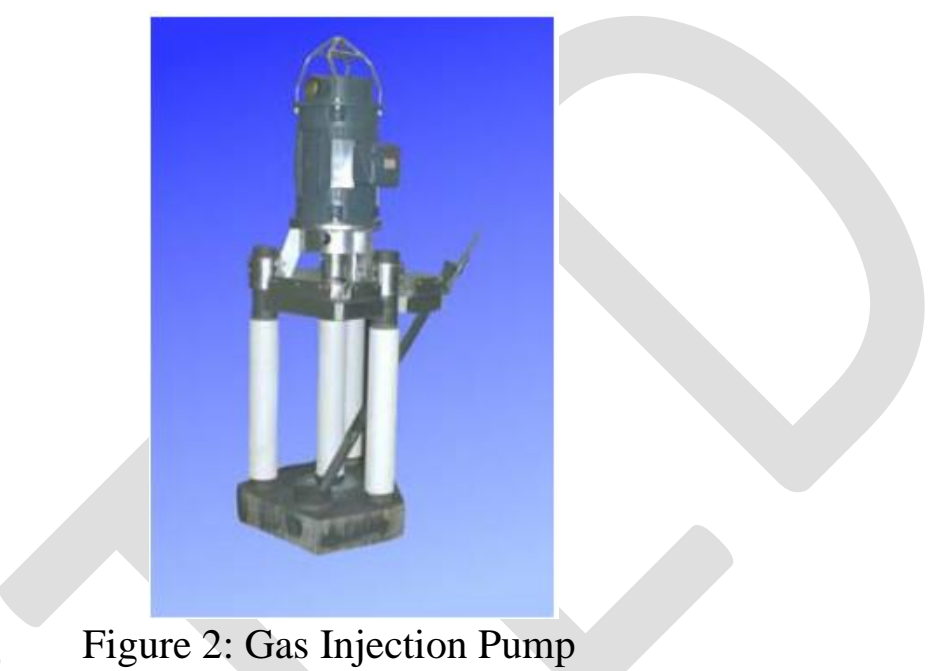

The developed nozzle design has solved several drawbacks of the historical gas injection pumps as it has attachedsnouts. In addition to that the accelerated, compressedaluminum flow provides superior degassing and demagging as the design modifications ofnozzle improved the mechanics and dependability of the system. The pump provides full spectrum of advantages for efficient heat transfer. These pumps are used as equipments to enhance melt cleanliness. This technology has displayed good application in melt cleaning to reduce alkali metal, hydrogen gas and inclusions. The injection pump also provides high recovery rates when used with vortexing systems that providesgood submergence of light scrap material

\section{OTHER TECHNOLOGIES FOR MELT CLEANING}

The formation of non-metallic inclusions during the alloy preparation by melting and refining is unavoidable. Sources of inclusions in these systems are: The refractory elements from the melting furnace and the reaction products of the alloying elements. A number of inclusions in the metal depend on the reactivity of the alloying elements and the metal production route. The effective treatment of melt determines the quality of the casted product[21]. The undesirable inclusions are brittle and affect the fracture resistance, fatigue resistance etc. of the product. These unwanted inclusions that are detrimental to the properties of the casted product must be eliminated before casting[20]. The most common type of inclusions: oxides, carbides, nitrides, borides, fluorides. The processing of aluminum alloys requires a series of melt processing techniques directed to achieve quality molten metal. Numerous new technological improvements have been established in processing the aluminum melts. The quality of the final component is to a large extent determined by effective melt treatments[22].

\section{Floatation}

The floatation technique of purification works on the similar principle of degassing. An impeller is rotated in the melt purging inert or reactive gasses. The inclusion removal works by the interaction of 
the gas bubbles with the solid impurities. Effective interaction is favoured by the distribution of small bubbles effectively throughout the melt. The solid particles effectively removed as they are pushed to the surface of the melt. Also, small sized inclusions $(<10 \mu \mathrm{m})$ are subjected to forced agglomeration. The effectiveness of the process depends on the size and distribution of the bubbles[23].

\section{Sedimentation}

The sedimentation is a simple technique by which the aluminium inclusions present in the aluminium melt settles down at the bottom. The settling of inclusions is based on the density, size, form and density. But the process is inefficient. The lighter inclusions whose density and masses are closer to that of aluminium remain in the melt. However, the method is commonly applied in industries due to their cheap processing[18].

\section{Filtration}

The filtration is the process of removing inclusions by a filter medium. The particles are removed in three different ways depending on the size of the particles and size of the pores in the filter[24].

\section{Bed Filters}

They are made up of $\mathrm{Al}_{2} \mathrm{O}_{3}$ with the size of 2-8 mm. They are in-line units and therefore need to be allocated a separate space. They are capable of handling $1000 \mathrm{t}$ a time. The effectiveness of the filter can be improved by varying the layer thickness, size, sequence of layers. These are capable of filtering inclusions up to $<20 \mu \mathrm{m}[12]$.

\section{Cake filter}

The first inclusions those are larger in size as the pore diameter, settle on the surface as a thin layer the thickness of this layer increases as the melt flow increases. Cake filtration is preferred for melt with larger inclusions[12].

\section{Ceramic Foam Filters}

Damoah et al[25] conducted a comparative study on the filtration efficiency of coated and uncoated ceramic filtering. He observed that the CFFs are capable of forming bridge like structures of inclusions over the top layer of the filters which increases the efficiency of the filtering operation. Through his comparative study, the author evinces that the CFFs coated with $\mathrm{AlF}_{3}$ has greater potential in removing dissolved impurities and non-metallic inclusions. The study has been supported in[26] that the removal efficiency of the $\mathrm{AlF}_{3}$-coated $\mathrm{CFF}$ depends exponentially on the residence time of the molten metal within the filter, the contact area of the filter by the molten metal and the mass transfer coefficient.

The efficiency (E) of the filter can be calculated by the following formula:

$$
E=\left(N_{i}-N_{o}\right) / N_{i} \times 100
$$

Where Ni and No refers to the number of inclusions present in per sq. mm. melt before and after filtration.

The filtration efficiency:

- Increases with increasing number of pores in the filter

- Increases with the decreasing melt flow rate.

- Increases with increasing residence time in the filter

Kennedy et al[27]have stated that the efficiency of the ceramic foam filters below the particle size of $10-30 \mu \mathrm{m}$ is less. Also in industries, where greater volumes of melts are filtered each day, problems like clogging, inclusions re-entrainment due to over loading affects the filtering efficiency. To address these issues latest methods of filtration are currently under research [28]. The filters commonly used in the aluminium castings are: Bed filters, bonded particle filters, strainer cores, metal or fiber glass screens, cartridge filters, Ceramic foam filters[29]. 


\section{FUTURE WORK}

Even though the process of recycling of aluminium alloys is being followed for many decades, it still requires consideration in several areas.

- Enhancing the recovery of metal from scraps.

- Reducing the consumption of energy.

- Chlorine purging for the removal of magnesium from the alloys must be neglected as it is not environment friendly.

- Knowledge on the influence of elements like $\mathrm{Cd}, \mathrm{Pb}, \mathrm{Se}$ etc. is very less.

- Magnesium lost in the form of dross and into the atmosphere must be reduced.

- Methods for the removal of trace elements such as $\mathrm{Zn}, \mathrm{Fe}, \mathrm{Cu}$ must be developed.

- Improvement in filtration techniques for the removal of large sizedharmful particles

- Improved testingfor the measurement of entrapped non-metallic inclusions

\section{CONCLUSION}

Due to the stringent demands of the government and the environment regulations on decreasing the emission of greenhouse gases and landfill space, recycling has gained huge focus recently. Recycling will certainly benefit the current situation of growing demand for aluminium products. The present paper covered the novel technology of application of gases for the removal of entrapped gases and inclusions. In addition to that several other techniques that are currently in application for the removal of harmful inclusions have also been briefed. However, research is still required in the areas of removal of trace elements, reducing the application of chlorine, removal of harmful inclusions, recovering magnesium and iron that are lost during the recycling process. Therefore, future researches must take into account of these factors. In addition to that, industries must take into account the recyclability of an alloy before introducing it into the market.

\section{REFERENCE}

[1] R. N. Lumley, Introduction to Aluminium Metallurgy. Woodhead Publishing Limited, 2011.

[2] S. Otarawanna and A. K. Dahle, Casting of aluminium alloys. Woodhead Publishing Limited.

[3] Z. Luo and A. Soria, Prospective study of the world aluminium industry, vol. 22951. Seville, 2008.

[4] F. Europe and N. America, "From Europe and North America," pp. 1-28, 2010.

[5] P. De Schrynmakers, "Life cycle thinking in the aluminium industry," Int. J. Life Cycle Assess., vol. 14, no. SUPPL. 1, pp. 12-15, 2009.

[6] G. Wallace, 4 - Production of secondary aluminium. Woodhead Publishing Limited, 2011.

[7] H. Amini Mashhadi, A. Moloodi, M. Golestanipour, and E. Z. V Karimi, "Recycling of aluminium alloy turning scrap via cold pressing and melting with salt flux," J. Mater. Process. Technol., vol. 209, no. 7, pp. 3138-3142, 2009.

[8] Y. Xiao and M. A. Reuter, "Recycling of distributed aluminium turning scrap q," vol. 15, pp. 963-970, 2002.

[9] Y. B. Zuo, B. Jiang, Y. J. Zhang, and Z. Fan, "Degassing LM25 aluminium alloy by novel degassing technology with intensive melt shearing," Int. J. Cast Met. Res. J. Int. J. Cast Met. Res., vol. 26, no. 1, pp. 1364-461, 2013.

[10] E. F. Emley, "Cleansing and degassing of light metals," Met. Technol., vol. 1693, pp. 118-127, 2016.

[11] L. Zhao, Y. Pan, H. Liao, and Q. Wang, "Degassing of aluminum alloys during re-melting," Mater. Lett., vol. 66, no. 1, pp. 328-331, 2012.

[12] B. Friedrich and Christoph krautlein, "Melt Treatment Of Copper And Aluminium - The Complex Step Before Casting," J. Metall.

[13] R. S. Henderson, D. V Neff, and C. T. Vild, "Recent Advancements in Gas Injection 
Technology Using Molten Metal Pumps," no. 1.

[14] E. Velasco and J. Nino, "Recycling of aluminium scrap for secondary Al-Si alloys.," Waste Manag. Res., vol. 29, no. 7, pp. 686-693, 2011.

[15] W. G. Jung, J. W. Lee, and W. Y. Kim, "Magnesium removal from molten aluminum by $\mathrm{Cl} 2$ bubbling," Met. Mater. Int., vol. 19, no. 6, pp. 1275-1281, 2013.

[16] L. Smith, "The Development of the for Demagging in the Secondary Aluminum Industry," no. September, 1978.

[17] E. A. Vieira et al., "Use of Chlorine to Remove Magnesium from Molten Aluminum," vol. 53, no. 3, pp. 477-482, 2012.

[18] O. Majidi, S. G. Shabestari, and M. R. Aboutalebi, "Study of fluxing temperature in molten aluminum refining process," vol. 182, pp. 450-455, 2007.

[19] N. I. Hong-jun, "Purification Effects of C $2 \mathrm{Cl} 6$ on A00 Aluminum," J. Shanghai Jiaotong Univ, vol. 17, no. 3, pp. 277-281, 2012.

[20] M. Maniruzzaman and M. Makhlouf, "Mathematical modeling and computer simulation of the rotating impeller particle flotation process: Part I. Fluid flow," Metall. Mater. Trans. B, vol. 33, no. 2, pp. 297-303, 2002.

[21] N. El-Kaddah, A. D. Patel, and T. T. Natarajan, "The electromagnetic filtration of molten aluminum using an induced-current separator," Jom, vol. 47, no. 5, pp. 46-49, 1995.

[22] L. W. and D. A. S. Shivkumar, "Molten Metal Processing of Advanced Cast Aluminum Alloys," J. Miner. Met. Mater. Soc., no. January, 1991.

[23] A. G. Szekely, "The removal of solid particles from molten aluminum in the spinning nozzle inert flotation process," Metall. Trans. B, vol. 7, no. 2, pp. 259-270, 1976.

[24] L. J. Gauckler, M. M. Waeber, C. Conti, and M. Jacob-Duliere, "Ceramic Foam For Molten metal Filtration," Jom, vol. 37, no. 9, pp. 47-50, 1985.

[25] A. Isc and S. Iscrs, "Proceedings of the 4th Annual ISC Symposium ISCRS 2010 April 21, 2010, Rolla, Missouri," 2010.

[26] L. Nana, W. Damoah, and L. Zhang, "AlF 3 reactive Al 2 O 3 foam filter for the removal of dissolved impurities from molten aluminum : Preliminary results," Acta Mater., vol. 59, no. 3, pp. 896-913, 2011.

[27] M. W. Kennedy, S. Akhtar, J. A. Bakken, and R. E. Aune, "Electromagnetically Enhanced Filtration of Aluminum Melts," Light Met. 2011, pp. 763-768, 2011.

[28] L. Nana, W. Damoah, and L. Zhang, "Removal of Inclusions from Aluminum Through Filtration."

[29] A. J. and E. E. S. Bell B. Davis, "Final Report On Refining Technologies Of Aluminum," vol. $21,2003$. 